\title{
BCL2L10 positive cells in bone marrow are an independent prognostic factor of azacitidine outcome in myelodysplastic syndrome and acute myeloid leukemia
}

\author{
Valérie Vidal ${ }^{1}$, Guillaume Robert ${ }^{2}$, Laure Goursaud ${ }^{1}$, Laetitia Durand ${ }^{1}$, Clemence \\ Ginet $^{2}$, Jean Michel Karsenti ${ }^{3}$, Frederic Luciano ${ }^{2}$, Lauris Gastaud ${ }^{4}$, Georges Garnier ${ }^{5}$, \\ Thorsten Braun ${ }^{6}$, Pierre Hirsch 7,8 , Emmanuel Raffoux ${ }^{9}$, Anne Marie Nloga ${ }^{10}$, \\ Rose Ann Padua ${ }^{1}$, Hervé Dombret ${ }^{9}$, Pierre Rohrlich ${ }^{3}$, Lionel Ades ${ }^{1,10}$, Christine \\ Chomienne ${ }^{1}$, Patrick Auberger ${ }^{2,3}$, Pierre Fenaux ${ }^{1,10}$ and Thomas Cluzeau ${ }^{1,2,3}$ \\ ${ }^{1}$ INSERM U1131, Institut Universitaire d'hématologie, Paris, France \\ ${ }^{2}$ INSERM U1065, Centre Méditerranéen de Médecine Moléculaire, Nice, France \\ ${ }^{3}$ Cote d'azur University, Nice Sophia Antipolis University, CHU of Nice, Nice, France \\ ${ }^{4}$ Centre Antoine Lacassagne, Service d'oncologie, Nice, France \\ ${ }^{5} \mathrm{CH}$ Princesse Grace, Service de Médecine Interne, Monaco, Monaco \\ ${ }^{6}$ Hôpital Avicenne, Paris 13 University, APHP, Bobigny, France \\ ${ }^{7}$ Hôpital Saint Antoine, Service d'Hématologie Clinique et de Thérapie Cellulaire, Paris, France \\ ${ }^{8}$ Sorbonne Universités, UPMC Univ Paris 6, UMRS 938, CDR Saint-Antoine, Paris, France \\ ${ }^{9}$ Hôpital Saint Louis, Paris 7 University, Service d'Hématologie Adulte, APHP, Paris, France \\ ${ }^{10}$ Hôpital Saint Louis, Paris 7 University, Service d'Hématologie Sénior, APHP, Paris, France \\ Correspondence to: Thomas Cluzeau, email: cluzeau.thomas@gmail.com
}

Keywords: MDS, AML, BCL2L10, IPSS, IPSS-R

Received: November 22, $2016 \quad$ Accepted: April 14, $2017 \quad$ Published: April 27, 2017

Copyright: Vidal et al. This is an open-access article distributed under the terms of the Creative Commons Attribution License 3.0 (CC BY 3.0), which permits unrestricted use, distribution, and reproduction in any medium, provided the original author and source are credited.

\section{ABSTRACT}

Azacitidine (AZA), the reference treatment for most higher-risk myelodysplastic (MDS) patients can also improve overall survival (OS) in elderly acute myeloid leukemia (AML) patients ineligible for intensive chemotherapy, but reliable biological markers predicting response and $O S$ in patients treated with AZA are lacking. In a preliminary study, we found that an increase of the percentage of BCL2L10, an anti-apoptotic member of the bcl-2 family, was correlated with AZA resistance. In this study, we assessed prospectively by flow cytometry the prognostic value of BCL2L10 positive bone marrow mononuclear cells in 70 patients (42 MDS and $28 \mathrm{AML}$ ), prior to AZA treatment.

In patients with baseline marrow blasts below $30 \%$, the baseline percentage of bone marrow BCL2L10 positive cells inversely correlated with response to AZA and OS independently of the International Prognostic Scoring System (IPSS) and IPSSrevised (IPSS-R). Specifically, OS was significantly lower in patients with more than 10\% BCL2L10 positive cells (median 8.3 vs 22.9 months in patients with less than $10 \%$ positivity, $p=0,001$ ). In summary, marrow BCL2L10 positive cells may be a biomarker for azacitidine response and $O S$, with a potential impact in clinical practice.

\section{INTRODUCTION}

Azacitidine (AZA) is the reference treatment for most higher-risk myelodysplastic syndromes (MDS) patients [1] which also improves overall survival (OS) in elderly acute myeloid leukemia (AML) patients ineligible for intensive chemotherapy (IC) [2]. In MDS, conventional biological factors included in the international prognosis scoring system (IPSS) are BM blasts percentage, karyotype and number of cytopenias. In the revised IPSS (IPSS-R), BM blasts percentage, cytogenetic risk group, hemoglobin, platelets and absolute neutrophil counts are 
used as parameters. The French Prognostic Scoring System (FPSS) is based on ECOG, presence of circulating blasts, red blood cell transfusion dependence and cytogenetic risk group. These scores can predict response and OS to AZA treatment [3-6]. Several genomic alterations detected by single nucleotide polymorphism (SNP) array and methylation profiles-such as TET2 mutations-have also been reported to predict better response to hypomethylating agents (HMA). Nevertheless, most of those results were not reproducible, did not allow to predict survival or were hardly applicable in routine practice [7-11]. An exception is the consistently poor prognosis associated with TP53 mutation, but this mutation is largely correlated with the presence of a complex karyotype [12].

BCL2L10 is an antiapoptotic [13-15] member of the bcl-2 family known to play a role in the chemoresistance of various cancers [16]. Overexpression of BCL2L10 has been reported to suppress apoptosis through inhibition of cytochrome c release from mitochondria [14]. The BCL2L10 protein undergoes several steps of regulation including final ubiquitinylation [17], confirming the interest to quantify this protein by flow cytometry (FCM) rather than to explore gene expression only [18]. In our retrospective study in 77 MDS patients evaluated at various time points after AZA onset (but generally not before AZA), we established by FCM that a high percentage of BCL2L10 positive bone marrow mononuclear cells (BMMC) was significantly associated with a lower response rate and shorter survival [18]. In this context, the aim of the present study was to prospectively validate the potential of BCL2L10 expression as a predictive biomarker of AZA treatment in MDS and AML.

\section{RESULTS AND DISCUSSION}

\section{Baseline patient characteristics}

Seventy MDS or AML patients, with a median age of 73 years (range 35-92) and M/F 41/29, were analyzed for bone marrow $(\mathrm{BM})$ cell BCL2L10 positivity before AZA treatment. WHO classification of MDS patients at onset of AZA therapy is summarized in Table 1: $37 \%, 13 \%, 22 \%$, $17 \%$ and $11 \%$ of patients had refractory anemia or refractory cytopenia with multilineage dysplasia (RA/RCMD), refractory anemia with excess blasts type 1 (RAEB-1), refractory anemia with excess blasts type 2 (RAEB-2), AML with less than $30 \%$ blasts and AML with more than $30 \%$ blasts, respectively. Cytogenetic risk according to IPSS and IPSS-R is also summarized in Table 1 . In patients with less than $30 \%$ blasts, IPSS was low, int-1, int- 2 and high in $10 \%, 41 \%, 24 \%$ and 25\%, respectively; and IPSS-R was very low, low, int, high and very high in $6 \%, 6 \%, 33 \%, 18 \%$ and $37 \%$, respectively. Patients were treated with AZA for a median number of 4 cycles (range 1-21). 39/70 (56\%) patients received 3 or more cycles of AZA.

\section{The percentage of BCL2L10 positive cells has an impact on response and OS with AZA}

No significant correlation was found between BCL2L10 positive cell percentage at AZA onset and bone marrow blast percentage. Fifty percent of patients were responders after at least 3 AZA cycles including $17 \%$ of complete remission. The median baseline number of BCL2L10 positive cells was 11\% (range 0-95) in AZA resistant patients vs 1\% (0-41) in AZA responders $(p=0.09)$. Patient characteristics according to BCL2L10 positive cells are shown in Supplementary Table 1. We observed a trend for AZA response depending to $\mathrm{BC} 2 \mathrm{~L} 10(p=0.08)$. But there is a significant difference in $\mathrm{CR} / \mathrm{mCR}$ rate between patients with more than $10 \%$ versus patients with less than $10 \%$ of marrow BCL2L10 positive cells, $0 \%$ versus $50 \%, p<0.0001$. Several studies have shown CR to be most predictive of long term outcomes [21]. In addition, hypomethylating agents were often considered prior to allo stem cell transplantation in order to obtain CR. Having a biomarker tool that could predict CR and/or marrow CR could be very important to define the best cytoreductive strategy before allo stem cell transplantation. If Using a cut off value of $10 \%$, OS was significantly lower in patients with more than $10 \%$ versus patients with less than $10 \%$ of marrow BCL2L10 positive cells: median 8.3 [5.9-10.6] vs 22.9 months [13.8-22.9], $p=0.001$ ) (Figure 1A). An increase of BCL2L10 positive cell percentage was observed during the course of AZA treatment (median 2\% [0-95] at AZA onset; 1\% [0-51] after 3 cycles; 12\% [0-95] after 6 cycles; 46\% [28-93] after 9 cycles), and this increase was significantly greater in resistant than in sensitive patients. Increase of BCL2L10, an antiapoptic protein, could contribute to the resistance to AZA that progressively develops during AZA treatment in MDS and AML patients, explaining why most responses are transient. Using this same cutoff value, we also observed a significantly lower OS in patients with more than $10 \%$ versus less than $10 \%$ marrow BCL2L10 positive cells at 6 months and 9 months (Figure $1 \mathrm{~B}$ and 1C).

Current results confirm prospectively, in a broader cohort of 171 MDS or AML patients, those of our first report. We also showed an increase of BCL2L10 positive cell percentage during AZA treatment, which was significantly higher in resistant than in responding patients. The median level of BCL2L10 expression was higher in AZA resistant patients (median 16\%) than in responders (median 5\%) $(p=0.005)$. Median survival after BCL2L10 evaluation was significantly shorter in patients with more than $10 \%$ versus patients with less than $10 \%$ BCL2L10 positive cells during AZA treatment (9 months [6-11.9] vs 15.6 months [9.6-21.7], $p=0.001)$. 
Table 1: Baseline patient characteristics in 70 MDS AML patients tested before AZA onset

\begin{tabular}{|c|c|}
\hline & $n=70$ \\
\hline Median age (range) & $73(35-92)$ \\
\hline $\mathbf{M} / \mathbf{F}$ & $41 / 29$ \\
\hline Median number of AZA cycles & $4(1-13)$ \\
\hline \multicolumn{2}{|l|}{ WHO Classification (\%) } \\
\hline $\mathrm{RA} / \mathrm{RCMD}$ & 37 \\
\hline RAEB-1 & 13 \\
\hline RAEB-2 & 22 \\
\hline AML (and AML with $>30 \%$ blasts) & $28(11)$ \\
\hline \multicolumn{2}{|l|}{ Cytogenetics according to IPSS (\%) } \\
\hline Good & 60 \\
\hline Intermediate & 24 \\
\hline Poor & 16 \\
\hline \multicolumn{2}{|c|}{ Cytogenetics according to IPSS-R (\%) } \\
\hline Very good & 2 \\
\hline Good & 57 \\
\hline Intermediate & 22 \\
\hline Poor & 15 \\
\hline Very poor & 4 \\
\hline \multicolumn{2}{|l|}{ IPSS (MDS and AML $\leq 30 \%)(\%)$} \\
\hline Low & 10 \\
\hline intermediate 1 & 41 \\
\hline intermediate 2 & 24 \\
\hline High & 25 \\
\hline \multicolumn{2}{|l|}{ IPSS-R (MDS and AML $\leq 30 \%)(\%)$} \\
\hline very low & 6 \\
\hline Low & 6 \\
\hline intermediate & 33 \\
\hline High & 18 \\
\hline very high & 37 \\
\hline Response to AZA (\%) & 50 \\
\hline
\end{tabular}

\section{Other prognostic factors and multivariate analysis}

The IPSS (HR $=1.83[1,11-3,05], p=0.02)$ and IPSS-R $(\mathrm{HR}=2.68[1.08-6.6], p=0.03)$ were correlated to OS, but not the FPSS. In multivariate analysis, in MDS and AML with less than $30 \%$ of blasts, BCL2L10 positive cells percentage was predictive for OS independently of the IPSS and IPSS-R (Table 2).

Therefore, in this prospective multicenter cohort, we found that the baseline percentage of BCL2L10 positive cells was inversely correlated with OS after AZA treatment in both MDS and AML patients, independently from IPSS and IPSS-R in MDS and AML with less than 30\% of blasts. The best prognostic cut-off value for BCL2L10 positive cells was $10 \%$.

We also confirmed the progressive increase in BCL2L10 expression during AZA treatment, observed in our previous retrospective series [18], with a greater increase in patients resistant to treatment.

The flow cytometry assay we used can be performed routinely in patients before the onset of AZA. Patients with more than 10\% BCL2L10 bone marrow mononuclear positive cells at AZA onset, who respond poorly to single agent treatment with AZA, may require alternative therapeutic approaches, including combinations of AZA with other drugs [22-28] which are currently under investigation. 
Table 2: Uni and multivariate analysis

\begin{tabular}{lcc}
\hline & $\begin{array}{c}\text { Univariate } \\
\text { analysis }\end{array}$ & $\begin{array}{c}\text { Multivariate } \\
\text { analysis }\end{array}$ \\
\hline IPSS & $\mathrm{HR}=1.83(1.11-3.05), p=0.02$ & $\mathrm{HR}=1.57(0.87-2.85), p=0.14$ \\
$\%$ of BCL2L10 positive cells & $\mathrm{HR}=2.31(1.32-4.05), p=0.004$ & $\mathrm{HR}=5.46(1.38-21.66), p=0.02$ \\
\hline & $\begin{array}{c}\text { Univariate } \\
\text { analysis }\end{array}$ & $\begin{array}{c}\text { Multivariate } \\
\text { analysis }\end{array}$ \\
\hline IPSS-R & $\mathrm{HR}=2.68(1.08-6.66), p=0.03$ & $\mathrm{HR}=2.16(0.83-5.62), p=0.12$ \\
\hline of BCL2L10 positive cells & $\mathrm{HR}=2.31(1.32-4.05), p=0.004$ & $\mathrm{HR}=7.31(1.52-35.25), p=0.02$ \\
\hline
\end{tabular}

\section{MATERIALS AND METHODS}

\section{Patients}

MDS and AML patients, diagnosed according to WHO criteria and treated with AZA, were prospectively included in 6 centers (University hospitals of Paris - Saint Louis, Paris Saint Antoine, Paris Avicenne, University hospital of Nice, Antoine Lacassagne center (Nice) and Princesse Grace hospital (Monaco)) in a cooperative study (https://clinicaltrials.gov/: NCT 01210274). Patients were treated with AZA ( $75 \mathrm{mg} / \mathrm{m}^{2} /$ day, 7 days every 4 weeks),
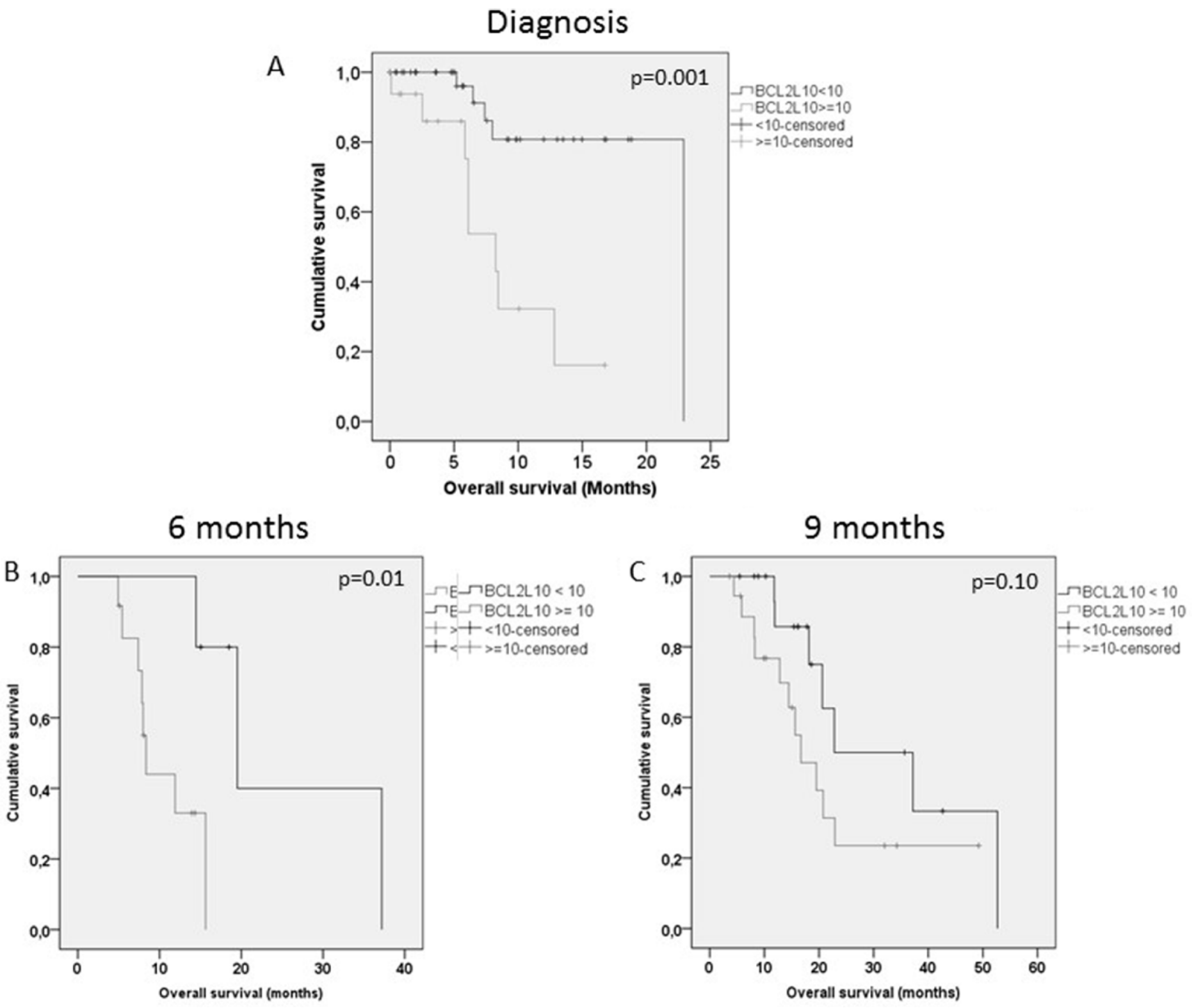

Figure 1: Overall survival according to BCL2L10 in patients at AZA onset, 6 months and 9 months. 
through the drug label in IPSS int-2 or high MDS, or AML with marrow blasts less than $30 \%$, and in compassionate use programs in AML with > 30\% marrow blasts and IPSS low and int-1 MDS. Patients had bone marrow evaluation every 3 cycles. Patients without response according to IWG 2006 criteria for MDS [19] or by Cheson et al. (2003) criteria for AML [20] at 6 cycles were considered as non-responders. Responses included in MDS: complete response (CR), partial response (PR), marrow $\mathrm{CR}(\mathrm{mCR})$, and hematologic improvement (HI). For AML, they included CR, CRi, and PR. Patients with stable disease (SD), progression or not evaluable after 3 or 6 cycles were considered as no responders.

\section{Quantification of BCL2L10 positive cells}

Flow cytometry was performed on fresh BMMC obtained before AZA onset, and after 3 or 6 cycles of treatment. BMMC were isolated by density centrifugation (Ficoll-Paque Plus). Cells were fixed by paraformaldehyde $3 \%$, permeabilized with Triton $0,1 \%$, incubated with an anti-human BCL2L10 rabbit antibody (Cell Signaling Technology, Beverly, MA, USA) followed by secondary donkey anti-rabbit FITC-labeled antibody and tested with a Canto Becton Dickinson flow cytometer. Examples of flow plots are shown in Supplementary Figure 1.

\section{Statistical analysis}

Continuous variables were described using median [Interquartile range] (minimum; maximum) and qualitative variables using counts and percentages. Noncontinuous variables were compared using the chi-square test. Mann-withney and kruskall-wallis tests were used for continuous variables. The best cut off value for BCL2L10 was defined using spline terms in a Cox model. Overall survival (OS) and post FCM evaluation were calculated from AZA onset, and from the date of FCM evaluation, respectively, and assessed by the Kaplan-Meier method. Statistical analysis was performed with SPSS v.22 (SPSS Inc., Chicago, IL, USA).

\section{Authors' contributions}

V.V., G.R., L.G., L.D., R.A.P and C.G. performed FCM; J.M.K., L.G., G.G., T.B., P.H., E.R., A.M.L., L.A., P.F. and T.C. collected bone marrow samples; G.R., L.G., L.D., R.A.P, C.G., J.M.K., F.L., L.G., G.G., T.B., P.H., E.R., A.M.L., H.D., P.R., L.A., C.C., P.A. and P.F. edited the manuscript; T.C., P.F and P.A. designed the study; and V.V, P.F and T.C. wrote the manuscript.

\section{CONFLICTS OF INTEREST}

All authors have nothing to disclose.

\section{REFERENCES}

1. Fenaux P, Mufti GJ, Hellstrom-Lindberg E, Santini V, Finelli C, Giagounidis A, Schoch R, Gattermann N, Sanz G, List A, Gore SD, Seymour JF, Bennett JM, et al. Efficacy of azacitidine compared with that of conventional care regimens in the treatment of higher-risk myelodysplastic syndromes: a randomised, open-label, phase III study. The lancet oncology. 2009; 10:223-232.

2. Dombret H, Seymour JF, Butrym A, Wierzbowska A, Selleslag D, Jang JH, Kumar R, Cavenagh J, Schuh AC, Candoni A, Recher C, Sandhu I, Bernal del Castillo T, et al. International phase 3 study of azacitidine vs conventional care regimens in older patients with newly diagnosed AML with $>30 \%$ blasts. Blood. 2015; 126:291-299.

3. Greenberg P, Cox C, LeBeau MM, Fenaux P, Morel P, Sanz G, Sanz M, Vallespi T, Hamblin T, Oscier D, Ohyashiki K, Toyama K, Aul C, et al. International scoring system for evaluating prognosis in myelodysplastic syndromes. Blood. 1997; 89:2079-2088.

4. Lamarque M, Raynaud S, Itzykson R, Thepot S, Quesnel B, Dreyfus F, Rauzy OB, Turlure P, Vey N, Recher C, Dartigeas C, Legros L, Delaunay J, et al. The revised IPSS is a powerful tool to evaluate the outcome of MDS patients treated with azacitidine: the GFM experience. Blood. 2012; 120:5084-5085.

5. Zeidan AM, Lee JW, Prebet T, Greenberg P, Sun Z, Juckett M, Smith MR, Paietta E, Gabrilove J, Erba HP, Tallman MS, Gore SD. Comparison of the prognostic utility of the revised International Prognostic Scoring System and the French Prognostic Scoring System in azacitidine-treated patients with myelodysplastic syndromes. British journal of haematology. 2014; 166:352-359.

6. Itzykson R, Thepot S, Quesnel B, Dreyfus F, BeyneRauzy O, Turlure P, Vey N, Recher C, Dartigeas C, Legros L, Delaunay J, Salanoubat C, Visanica S, et al. Prognostic factors for response and overall survival in 282 patients with higher-risk myelodysplastic syndromes treated with azacitidine. Blood. 2011; 117:403-411.

7. Itzykson R, Kosmider O, Cluzeau T, Mansat-De Mas V, Dreyfus F, Beyne-Rauzy O, Quesnel B, Vey N, GelsiBoyer V, Raynaud S, Preudhomme C, Ades L, Fenaux P, et al. Impact of TET2 mutations on response rate to azacitidine in myelodysplastic syndromes and low blast count acute myeloid leukemias. Leukemia. 2011; 25:1147-1152.

8. Bejar R, Lord A, Stevenson K, Bar-Natan M, PerezLadaga A, Zaneveld J, Wang H, Caughey B, Stojanov P, Getz G, Garcia-Manero G, Kantarjian H, Chen R, et al. TET2 mutations predict response to hypomethylating agents in myelodysplastic syndrome patients. Blood. 2014; 124:2705-2712.

9. Cluzeau T, Moreilhon C, Mounier N, Karsenti JM, Gastaud L, Garnier G, Re D, Montagne N, Gutnecht J, 
Auberger P, Fuzibet JG, Cassuto JP, Raynaud S. Total genomic alteration as measured by SNP-array-based molecular karyotyping is predictive of overall survival in a cohort of MDS or AML patients treated with azacitidine. Blood Cancer Journal. 2013; 3:e155.

10. Abaigar M, Ramos F, Benito R, Diez-Campelo M, Sanchezdel-Real J, Hermosin L, Rodriguez JN, Aguilar C, Recio I, Alonso JM, de las Heras N, Megido M, Fuertes M, et al. Prognostic impact of the number of methylated genes in myelodysplastic syndromes and acute myeloid leukemias treated with azacytidine. Annals of hematology. 2013; 92:1543-1552.

11. Meldi K, Qin T, Buchi F, Droin N, Sotzen J, Micol JB, Selimoglu-Buet D, Masala E, Allione B, Gioia D, Poloni A, Lunghi M, Solary E, et al. Specific molecular signatures predict decitabine response in chronic myelomonocytic leukemia. The Journal of clinical investigation. 2015; 125:1857-1872.

12. Bally C, Ades L, Renneville A, Sebert M, Eclache V, Preudhomme C, Mozziconacci MJ, de The H, LehmannChe J, Fenaux P. Prognostic value of TP53 gene mutations in myelodysplastic syndromes and acute myeloid leukemia treated with azacitidine. Leukemia research. 2014; 38:751-755.

13. Luciano F, Krajewska M, Ortiz-Rubio P, Krajewski S, Zhai D, Faustin B, Bruey JM, Bailly-Maitre B, Lichtenstein A, Kolluri SK, Satterthwait AC, Zhang XK, Reed JC. Nur77 converts phenotype of Bcl-B, an antiapoptotic protein expressed in plasma cells and myeloma. Blood. 2007; 109:3849-3855.

14. Ke N, Godzik A, Reed JC. Bcl-B, a novel Bcl-2 family member that differentially binds and regulates Bax and Bak. Journal of biological chemistry. 2001; 276:12481-12484.

15. Zhai D, Ke N, Zhang H, Ladror U, Joseph M, Eichinger A, Godzik A, Ng SC, Reed JC. Characterization of the antiapoptotic mechanism of Bcl-B. Biochemistry journal. 2003; 376:229-236.

16. Yasui K, Mihara S, Zhao C, Okamoto H, Saito-Ohara F, Tomida A, Funato T, Yokomizo A, Naito S, Imoto I, Tsuruo T, Inazawa J. Alteration in copy numbers of genes as a mechanism for acquired drug resistance. Cancer Research. 2004; 64:1403-1410.

17. Beverly LJ, Lockwood WW, Shah PP, ErdjumentBromage H, Varmus H. Ubiquitination, localization, and stability of an anti-apoptotic BCL2-like protein, BCL2L10/ $\mathrm{BCLb}$, are regulated by Ubiquilin1. Proceedings of the National Academy of Sciences of the United States of America. 2012; 109:E119-126.

18. Cluzeau T, Robert G, Mounier N, Karsenti JM, Dufies M, Puissant A, Jacquel A, Renneville A, Preudhomme C, Cassuto JP, Raynaud S, Luciano F, Auberger P. BCL2L10 is a predictive factor for resistance to azacitidine in MDS and AML patients. Oncotarget. 2012; 3:490-501. doi: 10.18632/ oncotarget.481.
19. Cheson BD, Greenberg PL, Bennett JM, Lowenberg B, Wijermans PW, Nimer SD, Pinto A, Beran M, de Witte TM, Stone RM, Mittelman M, Sanz GF, Gore SD, et al. Clinical application and proposal for modification of the International Working Group (IWG) response criteria in myelodysplasia. Blood. 2006; 108:419-425.

20. Cheson BD, Bennett JM, Kopecky KJ, Buchner T, Willman CL, Estey EH, Schiffer CA, Doehner H, Tallman MS, Lister TA, Lo-Coco F, Willemze R, Biondi A, et al. Revised recommendations of the International Working Group for Diagnosis, Standardization of Response Criteria, Treatment Outcomes, and Reporting Standards for Therapeutic Trials in Acute Myeloid Leukemia. Journal of Clinical Oncology. 2003; 21:4642-4649.

21. Komrokji RS, DeZern AE, Zell K, Al Ali NH, Estling C, Zimmerman C, Hand W, Brown F, Rizzo N, Barnard J, Roboz GJ, Garcia-Manero G, Steensma DP, et al. Validation of International Working Group (IWG) Response Criteria in Higher-Risk Myelodysplastic Syndromes (MDS): A Report on Behalf of the MDS Clinical Research Consortium (MDS CRC). Blood. 2015; 126:909-909.

22. Sekeres MA, O'Keefe C, List AF, Paulic K, Afable M 2nd, Englehaupt R, Maciejewski JP. Demonstration of additional benefit in adding lenalidomide to azacitidine in patients with higher-risk myelodysplastic syndromes. American journal of hematology. 2011; 86:102-103.

23. Raffoux E, Cras A, Recher C, Boelle PY, de Labarthe A, Turlure P, Marolleau JP, Reman O, Gardin C, Victor M, Maury S, Rousselot P, Malfuson JV, et al. Phase 2 clinical trial of 5-azacitidine, valproic acid, and all-trans retinoic acid in patients with high-risk acute myeloid leukemia or myelodysplastic syndrome. Oncotarget. 2010; 1:34-42. doi: 10.18632/oncotarget.100518.

24. Hyoda T, Tsujioka T, Nakahara T, Suemori S, Okamoto S, Kataoka M, Tohyama K. Rigosertib induces cell death of a myelodysplastic syndrome-derived cell line by DNA damageinduced G2/M arrest. Cancer Sciences. 2015; 106:287-293.

25. Xu F, He Q, Li X, Chang CK, Wu LY, Zhang Z, Liu L, Shi WH, Zhu Y, Zhao YS, Gu SC, Fei CM, Guo J, et al. Rigosertib as a selective anti-tumor agent can ameliorate multiple dysregulated signaling transduction pathways in high-grade myelodysplastic syndrome. Scientific reports. 2014; 4:7310.

26. Ades L, Guerci-Bresler A, Makhoul PC, Legros L, Delaunay J, Recher C, Desseaux K, Samey B, Chevret S, Fenaux P. A Phase II Study Of The Efficacy and Safety Of An Intensified Schedule Of Azacitidine (AZA) In Intermediate-2 and High Risk MDS Patients. Blood. 2013; 122:1513-1513.

27. Ades L, Recher C, Stamatoullas A, Bouabdallah K, Delaunay J, Dreyfus F, Vey N, de Renzis B, Raffoux E, Isnard F, Samey B, Chaffaut C, Chevret S, et al. A Phase I-II Study Of The Efficacy and Safety Of Lenalidomide (LEN) 
Combined To Azacitidine (AZA) In Higher Risk MDS and AML With Del 5q - A Study By The Groupe Francophone Des Myelodysplasies (GFM). Blood. 2013; 122:2750-2750.

28. Ades L, de Renzis B, Jeddi R, Delaunay J, Braun T, Berger MH, Stamatoullas A, Sanhes L, Samey B,
Chermat F, Meddeb B, Fenaux P. Azacitidine (AZA) Combined with Idarubicin in Untreated Patients with High Risk MDS - Results of a Phase I/II Study of the Groupe Francophone Des Myelodysplasies. Blood. 2012; 120:1720-1720. 